Europe's Journal of Psychology, 6(3), pp. 288-310

www.ejop.org

\title{
The Sense of Humor Questionnaire: Conceptualization and review of 40 years of findings in empirical research
}

\author{
Sven Svebak \\ Department of Neuroscience, Faculty of Medicine, The Norwegian University of \\ Science and Technology, Trondheim, Norway
}

\begin{abstract}
This paper presents the background for developing the Sense of Humor Questionnaire (SHQ), including ideas that guided the ambition to design a tool for assessment of individual differences in sense of humor that was relatively neutral to variations in culture, content and technique. The test was first organized into three dimensions of items, based on face validity of content, with items oriented to openness to ambiguity, preference for humorous situations and emotional suggestibility. The first revision reduced items from twenty-seven to twenty-two. A second revision presented seven items on each of three dimensions that were theoretically founded on ideas of person-situation interactions. Research found that items on meta-message sensitivity ( $M$-items) and liking of humorous situations (L-items) yielded fair alphas, whereas those on mirthful expression (E-items) did not. A review of research is presented based on scores from the $M$ - and L-items of the $S H Q$. The SHQ-6 is a short form including three items from the $M$ - and the L-dimensions, respectively. This scale has proven effective in research across a vide range of applications including the role of sense of humor in mood, coping, morbidity and mortality. An ultra-short version (SHQ-3) was included in a population health survey and provided descriptive evidence on the prevalence of sense of humor as well as the positive role for sense of humor in surviving into retirement. After age seventy this protective effect of sense of humor faded away.
\end{abstract}

Key words: Coping, Morbidity, Mortality, SHQ, SHQ-6, SHQ-3.

Sense of humor has been assessed in various ways for almost one hundred years. Thus, Kambouropoulou (1926) recruited one hundred female students at Vassar College to record instances of laughter throughout one week to provide estimates on individual differences in sense of humor. She also included a survey on 
extraversion-introversion according to the distinction proposed by Gustav Jung, and documented more laughter among the extrav erted students.

In the 1940's, several researchers proposed approaches to the assessment of individual differences in sense of humor by asking people to assess the funniness of jokes (Andrews, 1943; Cattell \& Luborsky, 1947; Eysenck, 1942; Wolff, Smith \& Murray, 1934). In this way, Andrews observed differences along six types of sense of humor (derision-superiority, reaction to debauchery, subtlety, play on words and ideas, sex, ridiculous-wise-cracks). Eysenck reported support for the idea that extraverted, aggressive and masculine personality traits were associated with a preference for emotional and sex-related jokes; whereas social shyness (introversion) was associated with a preference for cognitive and non-sex jokes. Cattell and Luborsky proposed thirteen dimensions along which individuals differed in their appreciation of jokes. Wolff et al. presented jokes about Jews to Jews and non-Jews and observed higher appreciation of such jokes among the latter as compared to the former. Thus, social identity and relations appeared to influence the appreciation of jokes above and beyond aspects of personality.

All these brave pioneering approaches had several limitations including the biased focus upon appreciation of jokes, rather than being open-minded, like Kambouropoulou was, in a neutral way to the whole range of forms, techniques and contents of humorous cognitive processes and utterances. It appeared risky to collect a sample of jokes from within a particular cultural setting and present them as a reliable, objective, and valid test on sense of humor internationally. This concern provoked a somewhat more neutral orientation to the assessment of individual differences in sense of humor, in the hope that assessment might be less sensitive to local culture, social identity and techniques in the appreciation of humor. It also appeared risky to focus upon individual differences in frequency of laughter, given the fact that a subjective state of mirth is not always reflected in overt laughter.

\section{An Exploratory Approach}

Humor is a social phenomenon that had been extensively explored throughout centuries, whereas sense of humor is an aspect of personality that was hardly explored and defined around 1970. Tentatively, and with a practical orientation to the need for operational assessment techniques, the first steps in the development of the Sense of Humor Questionnaire (SHQ) were taken in the preparation for a master's thesis at the University of Oslo in 1969 (Svebak, 1969). Twenty-seven items were constructed within each of three proposed broad components of sense of humor to 
explore the possibility for empirical assessment of individual differences. These three components were (1) openness to ambiguity), (2) liking of humorous situations and others and (3) emotional suggestibility/permissiveness. Ninety-six university students completed the survey.

Biv ariate correlational findings revealed that the sum of scores in one group of items correlated significantly with the sum of scores in the two other groups of items $(r=.74$ to .78, $\mathrm{p}<.0011$. In this way, the three groups of items represented a broad conceptual approach to the assessment of potential aspects of sense of humor, rather than different orthogonal dimensions. Also, twelve items were better than the remaining fifteen at discriminating between individuals with high versus medium and low total scores. Four of these were social attitude items, whereas three were affective items and five were openness to ambiguous meta-communication items. The distribution of total scores met require ments for being a normal distribution.

Tow ard a Conceptual Basis for the SHQ

The first step in improving the unpublished SHQ from the master's thesis focused on openness to ambiguity and emotional suggestibility. Conceptually they were oriented to the appreciation of ambiguity, socio-emotional suggestibility and expressiveness as general aspects of personality. One apparent problem with these broad components was reflected in the high and positive correlations between scores on the three dimensions (see above). Also, total items were reduced from twenty-seven to twenty-two. These selected items presented the participant with statements that addressed more specifically the content that was assumed to be of relev ance to differences in sense of humor.

A conceptual analysis guided the revision. A model was proposed (Svebak, 1974a) for psychologic al components that might be of particular importance to describing individual differences in humor appreciation, mirthfulness and related overt laughter. It was presented as a "theory of sense of humor," despite the fact that a theoretical analysis of the concept itself was not the focus of this model. However, It proposed a cognitive process where any social phenomenon (identity, action, person, status, prestige, power, social system, ideology) is in some way presented and then redefined to cause diminishment through meta-communication. It took several more years before a precise conceptual analysis of the cognitive structure in humorous experience was published (see Apter, 1982). 
The proposed model defined two complimentary sets of three variables that modulated the response output to any potentially humorous stimulus. One set addressed situational characteristics and included the explicitness of any humorous meta-message as a stimulus, whereas the two other counted interpersonal likings and socio-emotional permissiveness (e.g., being with friends in a playful context will increase likelihood of overt and shared laughter in response to an intended humorous remark from one of the inmates). Moreover, the model proposed a related set of person-variables that would define the sense of humor of any particular individual and, therefore, explain the range of individual differences in response to any potentially humorous stimulus. The most important of these person variables was proposed to be the habitual sensitivity to humorous meta-messages that give rise to the experience of mirth. Overt laughter will depend upon the strength of two more variables, one being habitual liking of comical situations and interactions, and the other being habitual overt laughter response permissiveness. Thus, the latter three variables were proposed as dimensions of sense of humor related to their more or less activ ating situational equiv alents, respectively.

Tests on humor appreciation, such as the Humor Appreciation Test (O'Connell, 1969) and the Mirth Response Test (Doris \& Fierman, 1956), appeared to be ignoring contextual social characteristics. In this way, the proposed model provided for a better understanding of individual differences in overt mirthful behaviour than was possible in approaches where the potentially humorous material was presented as a stimulus with no attention given to other situational and individual variables that might modulate any covert or overt response.

Items were organised along the three proposed dimensions of conceptual content (Svebak, 1974b) based upon face validity to distinguish between (1) sensitivity to humorous content and meta-messages (M-items), (2) attitude toward humorous people and situations (L-items) and (3) openness to the expression of mirth (E-items). Four-step scoring formats were given to all items. The first group of items is illustrated by: "When I go to the movies I prefer to know beforehand what kind of a story I am to see" (Total agreement = 1; Total disagreement $=4$ ). Items in the L-dimension are illustrated by: "Fun is always aimed at hurting some body" (Total agreement = 1; Total disagreement $=4$ ). The expressiveness items are illustrated as follows: "Do you at times laugh so much that it actually hurts?" (Very seldom = 1; Very often =4). There were seven $\mathrm{M}$-items, six L-items and nine E-items.

It soon became evident by face validity that the content of some items within one dimension could be seen as fitting well also into another dimension. One example 
from the M-dimension is the item "Do you easily laugh?" that might fit better within the E-dimension despite the initial idea that laughter often is the consequence of experiencing a cognitive meta-message. Likewise, in the L-dimension, the item "I prefer to work according to fixed rules and arrangements" might better be seen as an ideal item for the E-dimension due to the inherent orientation to a lifestyle opposite to impulsivity and non-planning, despite the initial intention that people who agree to this item would likely avoid impulsive social interactions that provoke laughter. Or it could equally well fit in with the $\mathrm{M}$-items because of its orientation to the avoidance of ambiguity. And, finally, the E-item "I have noticed that those who tell the jokes laugh the most themselves" might better fit within the L-dimension, despite the initial intention that agreement might reflect habitual need for socioexpressive inhibition. Alternatively, it might be seen as an item fitting within the $M$ dimension due to agreement reflecting poor understanding of humorous metacommunication in general.

The obvious dimensionality problems with the first published version of the SHQ came on top of the complic ating fact that there were still uneven numbers of items in the three sections of the SHQ. In light of these problems, scores predicted surprisingly well the amount of laughter in a laboratory experiment with exposure to video presentations of some of the most hilarious candid camera sequences from Norwegian TV in the early 1970ies (Svebak, 1974b). Ninety-six university students completed the 22-item SHQ and thirty were invited to take part in the laboratory experiment. They were recruited from across the whole range of high to low total SHQ-scores, with ten from the highest, middle and lowest one third of the distribution, respectively, and they were balanced for gender. For the initial sample of ninety-six students, scores on the three dimensions correlated moderately positively with each other (r's from .29 to .38).

L-scores positively predicted amount of laughter among the males (<.05), whereas the E-scores positively predicted laughter for the females $(p<.01)$. From a theoretical point of view, these findings were interesting for two reasons. First, they supported the assumption in the theoretical model (Svebak, 1974a) that occurrence of laughter is strongly dependent upon the laughter inhibiting tendencies of an individual (the Land E-components), and less dependent upon the M-component, which gives rise to the subjective experience of mirth even when mirthfulness is not displayed to others. Secondly, the structure of the findings could be taken as confirmation of the contemporary sex role stereotypes, with males being relatively more strongly committed to the social context as opposed to females being more directly sensitive to the emotional consequence in their overt responses to humor. 
The lack of predictions for the $M$-item scores, however, may not have reflected a structural relationship with the L- and E-components of the sense of humor concept. At a more trivial level, it may have been due to a too broad orientation for the items included in this dimension, as items on general serious-mindedness were also employed here (e. g. item 7:"We live in a world filled with so many serious problems and challenges that we ought to spend less time on trivial amusements" (Svebak, 1974b).

Revision of the SHQ

The next revised SHQ (Svebak, 1974c) presented seven items on each sub-scale and kept the four-step scoring format from the initial SHQ. An example from the dimension of sensitivity to humorous messages ( $M$-items) is item $M-1$ : "Do you easily recognize a hint like a twinkle or slight change in emphasis as a mark of humorous intent?" Another example is item M-4: "Would you say that you have much cause for amuse ment during an ordinary day?" Whereas the first item may tap into perceptual sensitivity, the second example may be more oriented to assessing the degree of a playful humorous attitude to everyday life.

The habitual liking of comical situations and humorous others dimension (L-items), is illustrated by item L-3: "Persons who are always out to be funny are really irresponsible types not to be relied upon," and by item L-7: "It is my impression that those who try to be funny really do it to hide their lack of self-confidence". Notice the negative orientation to the L-items that is due to the fact that a wider distribution of scores was obtained with this orientation than with a positive one.

The third set of items are oriented to the habitual tendency of an individual to permit or suppress emotional impulses of mirthfulness and joy in general (E-items). These items are illustrated by E-2: "I appreciate people who tolerate all kinds of emotional outlets?" and E-4: "Do you sometimes find yourself laughing in situations where laughter is quite out of place?"

This revised SHQ was administered in an exploratory manner to seventy-one university students in physical sciences and ninety-one in social sciences, balanced for gender. Results showed that the three sets of items contributed in a balanced way to the total score. Only item E-5 presented a skewed distribution with low scores ("If you had an unrestrained fit of laughing, would you later suffer from misgivings in case others think you were a bit of an exhibitionist?"). Scores on the $M$-items correlated moderately with the scores on the L- and E-items ( $r=.34$ and .27 , respectively); 
Whereas scores on the E-items were unrelated to those on the L-items. This pattern of relations supported the point that overt laughter is a poor indicator of sense of humor, as there are many sources of laughter beyond humorous cognitive processes (see e.g. Giles \& Oxford, 1970). In retrospect, there were also obvious content validity problems with some E-items that were carried over from the previous versions, such as E-7: "Do you consider yourself to be of an impulsive nature?" Despite these problems with the E-items, findings from the L- and E-items were consistent with social stereotypes that flourished in the 1970's for gender and recruitment of psychologically somewhat different types of students into physical and social sciences.

A more extensive series of validating studies of the revised SHQ came from Rod Martin and his collaborators and are presented in the book based upon his Ph.D. (Lefcourt \& Martin, 1986). Generally, the internal consistency of the $M$ - and L-items were acceptable (alphas in the .60's and .70's), whereas it was poor for the E-items. One-month retest reliability was also good (M-items: .78; L-items: .58; E-items: .58). Due to lack of internal consistency for the E-subscale, only the $\mathrm{M}$ - and L-items were included in their further research. Scores on these two subscales correlated significantly with scores on the Humor Coping Scale (HCS); whereas only $M$-item scores correlated significantly with the Situational Humor Response Questionnaire (SHRQ). Also, the $M$ - and L-scores correlated with peer ratings on sense of humor (responsiveness to humor), with slightly higher coefficients for the L- than for the Mitems. Humor production, however, yielded a significant correlation only with the Litems. From a theoretical point of view, high sensitivity to humorous meta-messages should be expected in people who score high on the $\mathrm{M}$-items and high or low on humor production. For the revised SHQ, several other studies have tested corr elations of scores with other measures of sense of humor. The $M$ - and L-items have consistently come out with the highest coefficients (see Ruch, 1998).

SHQ, Gender, Self-esteem and Personality

Deaner and McConatha (1993) studied the association of sense of humor with depression and personality in thirty-eight male and ninety-one female college students. They all completed three questionnaires for the assessment of sense of humor, including the SHQ (Svebak, 1974C), one depression scale and the Eysenck Personality Inventory. Results indicated that students scoring high on all humor scales also tended to score high on the extraversion and emotional stability scales, and lower on the depression scale. Gender was of no significance to these associations. 
Franzini (1996) measured sense of humor with the SHQ (Svebak, 1974C) and a selfrated sense of humor estimate among 175 females who also completed femininity and attitudes toward women scales. The purpose was to evaluate the assumption that feminist women lack a sense of humor. Her results stated that scores on the SHQ were positively correlated with scores on self-rated sense of humor as well as an item on how often others laugh at their humorous remarks. In this way, there was validating support to the SHQ, whereas no support was found for the idea that feminist women have a low sense of humor.

Two years earlier, Franzini and Haggerty (1994) compared sense of humor across mixed gender groups of program managers ( $N=34)$, humor seminar students ( $N=29$ ) and undergraduates $(\mathrm{N}=26)$. Results from one-way analyses of variance indicated that females scored higher than males on the L-items of the SHQ (1974C), suggesting that females, on average, tended to enjoy humorous interaction more than males. The greater salience of the social component of sense of humor among females appears to be a robust finding that has also been supported in studies of children, with a preference for hostile humor relatively more prevalent among boys (Bergen, 2009). Franzini and Haggerty reported no other gender difference. For participant groups, humor seminar students scored higher than the other two groups on the Mitems and on the total SHQ, suggesting that the humor seminar students were particularly sensitive to potential sources of humor in everyday life.

Kuiper and Martin (1993) investigated the association of sense of humor with selfesteem in undergraduate students in London, Ontario. These participants completed four scales on sense of humor including the $M$ - and L-item sub-scales of the SHQ. They also completed a series of sixty self-descriptive adjectives on actual versus ideal self. Results indicated that students scoring high on the humor scales also scored low on discrepancy between ideal and real self. And those scoring high on the humor scales were less likely to reflect unrealistic, dysfunctional and perfectionist standards of self-image.

The idea of an association of sense of humor with mental health, on average, has been moderately supported in empirical research. Kuiper and Martin (1988) compared results from five student samples to see how well sense of humor and dispositional optimism related to subjec tive wellbeing. The humor scales included the Humor Coping Scale, Situational Humor Response Questionnaire and the M- and Lsub-scales of the SHQ. The findings revealed that scores on the humor scales were only moderately associated with optimism $(r=.18$ and .17 for the L- and M-items, respectively); and that they were only moderately associated with a number of 
indicators of wellbeing, including self-acceptance, positive relations with others, mastery, autonomy and goals in life, in most of the samples (overall $r=.28$ and .39 for the L- and $\mathrm{M}$-scores, respectiv ely). In one sample (79 females, 57 males; mean age 19.7), scores on the $L$ - and $M$-items correlated negatively with scores on a measure of social avoidance and distress ( $r=-34$ and -.44, respectively), and so did scores on the Coping Humor Scale and the Situational Humor Response Questionnaire. Optimism turned out to be more strongly associated with these indicators of psychologic al wellbeing than were measures of sense of humor (see Kuiper \& Martin, 1998).

SHQ and Moderation of Stress

The first stress-mo derating study using the SHQ, was presented by Lefcourt and Martin (1986), and this study focused upon moods (Profile of Mood States: McNair, Lorr \& Droppelman, 1971) over the last month in fifty-six university students who also completed the SHRQ, CHS, SHQ and the Life Events of College Students scale (Sandler \& lakey, 1982). Results confirmed a significant stress-moderating role for the L-items upon negative mood, due to the interaction of L-scores with negative life event scores. Negative mood was less likely reported in students with high negative life events, provided they also scored high on the L-items. Similar moderating effects were seen for scores on the SHRQ and CHS, but not for the M-items of the SHQ.

A few years later, Martin and Dobbin (1988) reported similar moderating effects of sense of humor upon consequences of daily hassles and their effects upon salivary immunoglobulin A (Ig-A) in thirty participants who also completed the SHRQ, CHS and $S H Q$. Results confirmed the moderating effect of sense of humor when assessed by the SHRQ, CHS and, most signific antly $(p<.01)$, for the $M$-scores of the SHQ.

The SHQ and Negative Moods

Sense of humour is not a synonym for positive mood but, rather, an aspect of personality that may protect against dramatizing interpretations of everyday frustrations and mishaps that might otherwise facilitate negative moods. In this way, sense of humor has long been acknowledged as a form of defence mechanism that helps people cope with negative life events. This perspective on sense of humor has gained support in several studies, and some of them included the SHQ. As one illustration, Kuiper, Martin and Dance (1992) tested the association of sense of humor with quality of life using a set of humor questionnaires (CHS, SHRQ, SHQ) and measures of positive and negative life events. Results confirmed a stress-buffering 
role for sense of humor. Significant interactions were found between stressful negative life events and sense of humor in predicting positive affect. Under stressful negative life events, those individuals scoring high on sense of humor reported more positive affect than those scoring low on sense of humor. Of particular interest, this buffering role was most evident for scores on the $M$-items of the SHQ.

The SHQ and Subjective Health

Sense of humor might reduce the risk of ill health in a number of potential ways. These were outlined in detail by Martin (2007) and include potential beneficial effects of laughter, as well as more indirect effects of sense of humor such as the often defusing cognitive coping style in sense of humor, the interpersonal mechanisms that might provide increased social support in humorous individuals, and promotion of a healthy lifestyle that may be associated with high sense of humor.

Generally, results from empirical studies offer very little direct support for any of these hypotheses. However, the findings obtained from seventy-one university students in a 1993 study by Svebak supported a moderating role for sense of humor in prevalence of bodily complaints, when exposed to enduring stressful life events. Participants completed the SHQ, the Tension and Effort Stress Inventory (TESI: see Svebak, 1993) and the Ursin Health Inventory (UH: Ursin, Endresen \& Ursin, 1988). Findings supported a stress-moderating effect of sense of humor upon musculoskeletal complaints $(p<.03)$, upper as well as lower gastrointestinal complaints $(p<.0001)$ and immunerelated complaints $(p<.0006)$, with lower complaint scores under stress in participants with high scores than in those with low scores on the L-items of the SHQ. The stressmoderating effect of sense of humor (L-scores) accounted for a $7 \%$ increase in the predicted variance for musculoskeletal complaints, more than a $20 \%$ increase in the variance for gastrointestinal complaints, and a $19 \%$ increase in the variance for immune-related complaints.

The role of sense of humor in subjective health was also addressed in a sample of one hundred and thirty-two undergraduates who completed scales on sense of humor, including the $M$ - and L-items of the SHQ, and a broad range of questions on physical symptoms, health-related lifestyle, and fear of death and disease (Kuiper \& Nicoll, 2004). Results indicated a moderately reduced fear of death and disease among those scoring high on the $M$ - and L-items of the SHQ. These individuals were also less preoccupied about bodily functions and states than were those scoring low 
on these items, and scores on the L-items were high among students reporting reduced concern about pain and general worry about their health.

\section{From SHQ to SHQ-6}

Several concerns provoked a third revision of the SHQ from the master's thesis. One was the need for a shorter scale. The ultimate goal of item reduction was to increase the possibility for inclusion of a short measure of sense of humor in a survey without reducing the motivation to comply or the percentage of participation. A second concern was the poor internal consistency of the E-items. The high number of different causes of laughter, beyond that of mirthful laughter due to experience of humor, meant that achievement of a culturally neutral sub-scale on humor causations of laughter might be difficult to achieve. In light of these two major concerns, the third revision aimed at developing a shorter scale with only items from the $\mathrm{M}$ - and L-subscales included.

This third revision was based on scores from more than one thousand high school students who completed the 21-item version of the SHQ (Svebak, 1996). Although this cohort was not a representative sample of the population, the completion rate was very high (above $90 \%$ ). The initial factor solution in this sample yielded a first factor with nine items loading above .65. There were three $M$-items, four L-items and two E-items in this factor. A second factor had three $M$-items with loadings above .62. In short, the pattern of findings supported a preference for one main factor composed of three $\mathrm{M}$-items and three L-items, based upon particularly high factor loadings. These six items where then pooled together and subjected to a confirmatory factor analysis, with a resulting Cronbach alpha of .85 (N=995). Gender had no effect on this internal consistency measure (males: $\alpha=.83$; females: $\alpha=.87$ ). All six items presented unrotated factor scores above .69 , with the rotated factor loadings clearly reflecting the distinction between $M$ - and L-items. Scores were summed across the six items and tested for correlations with the original SHQsubscale scores. As expected, high coefficients were obtained for the SHQ-6 with the $M$ - and L-scores (.74 and .80, respectively), whereas the E-subscale coefficient was lower (.59). Also, high scores on the SHQ-6 were seen among students scoring low on depression (-.42) and high on life regard (meaningful frames in life: .24; goal fulfilment: .24).

Overall, it was concluded that the SHQ-6 emerged with good internal consistency and some indication of specificity. Most of all, the short list of items promised high efficacy for the assessment of sense of humor in survey studies where high numbers 
of total items reduce motivation and compliance among participants. Further support for the reliability and validity of the SHQ-6 has come from many studies including the Humor Styles Questionnaire (Martin, Puhlik-Doris, Larsen, Gray \& Weir, 2003). Scores on the SHQ-6 correlated significantly with scores on the affiliative $(r=$ .54) and self-enhanching ( $r=.45)$ sub-scales, but not with scores on the two hostile sub-scales (aggressive: $r=.12$; self-defeating: $r=.16$ ). As such, the SHQ-6 generally appe ars to be oriented tow ard measuring a friendly humor style.

The SHQ-6 in Adolescent Health

Three studies have been published using the SHQ-6 in a sample of more than one thousand high school students in Norway. A survey measure was distributed to 1,162 students and scored by 1,069 students in class (response rate of $92 \%$ ). They were split between 698 students in an urban setting and 372 in a rural setting; and represented a total of 524 girls and 545 boys balanced across the two settings.

The first study was purely descriptive and uncovered a surprisingly strong difference in SHQ-6 scores between students living in urban versus rural environments (Naper Jensen, Svebak \& Götestam, 2004). The urban students scored, on average, around 19. This was opposed to the urban students who scored, on average, around 15 with no significant difference between males and females. The urban versus rural environments also showed highly significant differences in depression (Zung selfrating depression scale), dysphoric moods (Eysenck Neuroticism scale), meaningfulness in life (Life Regard Index with sub-scales for Goals in life and Achievement of goals) and bodily complaints (more complaints among urban adolescents with highest scores among these females). Highly signific ant correlations emerged for scores on depression with sense of humor $(-.42, p<.00004)$ and overall meaningfulness $(-.43, p<.00004)$. The overall pattern in these results clearly favoured the rural setting for adolescence. Differences suggested better mental as well as bodily health and greater coherence in everyday life as compared with the urban setting that appeared to offer inferior conditions for the facilitation of meaningfulness and sense of humor.

A second publication from this sample of adolescents focused upon bodily complaints and their relationships with the psychological variables of perceived stress, related efforts to cope, meaningfulness and sense of humor (Svebak, Götestam \& Naper Jensen, 2004). Confirmatory factor analyses of the two subscales of the Life Regard Index suggested low internal consistencies ( $\alpha=.62$ and 63). A procedure of stepwise item deletion was therefore performed until the internal 
consistency of the remaining items reached the recommended criterion of .70. One subscale was named Meaning $(\alpha=.73)$ and the other was named I mportance $(\alpha=$ .76). The Meaning scale reflected an overriding perspective on life, whereas the Importance scale reflected degree of importance attributed to activities of everyday life.

Due to the higher complaint scores among females, effect of gender $(p<.0004)$ was eliminated in hierarchical regression analyses. Level of perceived stress was highly significant among adolescents scoring high on complaints $(p<.0004)$. A direct effect of sense of humor upon bodily complaints was not confirmed. However, high scores on Meaning were associated with low complaint scores $(p<.009)$. Furthermore, the scores on Importance interacted significantly with sense of humor to explain significant amounts of variance in bodily complaints $(p<.001)$. High complaint scores were seen among adolescents scoring high on Importance and low on sense of humor or low on Importance and high on sense of humor. There is no previous published research on these relationships for this age cohort. We therefore speculated that the buffering role for sense of humor upon bodily complaints among adolescents is moderated by the level of importance attributed to activities of everyday life. With low sense of humor low importance is to be preferred, and with high sense of humor high importance is to be preferred to reduce risk of bodily complaints. In this way, results confirmed previous findings from adult samples were complex relations have been reported for sense of humor with bo dily complaints.

\section{SHQ-6 and Personality}

Recently, Randler (2008) reported from a survey of one hundred and ninety seven students who completed a scale on morningness-eveningness, the short Big Five personality inventory and the SHQ-6. Results supported a significant association of evening orientation with high sense of humor scores, and this association was significant after controlling for the personality dimensions. However, this association was significant only among the women and for the L-items. Again, this association provides support to a gender difference where females appear to appreciate humorous social interaction more than males, and the females with an evening orientation may have found the best opportunities for such social interaction in the evenings.

Recruitment of employees often involves personality assessment to reduce turnover. Lange and Houran (2009) investigated the importance of personality traits among one hundred and eight managers and human resource professionals who rated the 
perceived importance of thirty-one performance traits for line, middle and senior employees. Strong consensus was found, and the importance of traits differed across the three groups of employees. Non-social skills, ethical awareness, self-motivation, verbal ability, problem solving and creativity were rated as more important for higher level employees, whereas service orientation, communication style, agreeableness, sensitivity to diversity and sense of humor were rated as more important for lower level employees. Age and gender of the respondents were not related to these findings.

Beermann and Ruch (2009) compared scores on twelve survey measures of sense of humor to determine how humor may be related to virtues and vices. Sixty female and sixteen male university students in psychology took part in the first study, with results showing a pattern for all six SHQ-items to be attributed to the positive vicevirtue end of the scale. In contrast, a scale on jokes and tricks had items where all fell in the negative end of the vice-virtue dimension. Six male and eleven female students in philosophy and theology participated in the second study where items were assessed across all the six classical virtues (wisdom, courage, humanity, justice, temperance, transcendence). Results showed that most items did not load any particular virtue, and that some items loaded slightly or moderately on wisdom, courage, humanity or transcendence. In conclusion, these results supported the position that items in current sense of humor scales reflect, to varying degrees, a sense of humor that is vice and virtuous; and that the SHQ-6 items are in the vice$v$ irtuous end of the distribution. This finding is in accord with the positive correlation of SHQ-6 scores with scores on affiliative humor styles (see above).

\section{SHQ-6 in Coping with Life Stress and Bodily Complaints}

The SHQ-6 was included in a controlled field study that tested effects of implementing school nursing in urban Norwegian high schools (Svebak, Naper Jensen \& Götestam, 2008). This report appears to be the first controlled study to test such effects and also included survey measures on perceived stress, efforts invested to cope, positive and negative moods, and health complaints. The survey was administered in class, at both baseline and one year later. One sample of students was offered school nursing and students in other classes were not (total $N=104$ balanced for gender). At baseline, there was no association between being or not being offered the school nursing service and sense of humor. Surprisingly, after one year, those without school nursing had significantly raised their sense of humor scores with no change in the experimental group. One might speculate that school nursing may take some of the burden of coping with adolescence off the students and that 
those with no such service had to invest more efforts in developing their own intrinsic coping skills, including sense of humor. This pioneering study calls upon replication on a larger scale and in a diversity of cultural settings.

Helvik, Jacobsen, Svebak and Hallberg (2007) studied the importance of sense of humour in coping with he aring impairments. Consecutive patients ( $N=343$ ) over one year at an outpatient hearing impairment clinic completed the SHQ-6, the Communication Strategies Scale (CSS), with subscales for maladaptive behaviour as well as verbal and non-verbal strategies. The findings showed that high scores on sense of humor were associated with being female and a younger age. Also, frequent use of maladaptive behaviour was related to younger age, long duration of hearing impairment and low sense of humor. Furthermore, maladaptive behaviour, expressed as negative reactions to stressful events in communication, was negatively associated with sense of humour. These results tentatively suggested a role for sense of humor in the choice of communication strategies among people coping with hearing impairment. When corrected for age, degree of hearing impairment and duration of impairment, sense of humor still significantly explained the presence of adaptive behavioural coping strategies.

One study tested the association of pain from gallbladder stones with scores on sense of humor (SHQ-6) and measures of positive coping resources (Life Regard Index, Sense of Coherence Scale), as well as negative coping resources (EPQNeuroticism, Tension and Effort Stress Inventory: Svebak, Søndenaa, Hausken, Søreide, Hammar \& Berstad, 2000). Twenty-eight patients with recent acute cholecystitis were recruited consecutively into the study at the Haukeland University Hospital. Ultrasonography defined number and size of stones as well as degree of damage to the gallbladder wall. All patients completed a pain index of four items related to pain in the upper right abdominal quadrant. Surprisingly, scores on the pain index were uncorrelated with objective indicators from ultrasonography on the severity of the gallbladder condition. Instead, multiple regression analyses of explained variance in the pain index showed that the positive coping resource model with Life Regard Index and SHQ-6 (the three L-items in particular) accounted for $40 \%$ of the variance in pain. The higher these scores, the lower the reported pain, and both variables accounted for their equal share of the variance. Conversely, the negative coping resource model with EPQ-N (dysphoric nervousness) and negative moods in general, accounted for $45 \%$ of the variance in pain, most of this latter variance being accounted for by the EPQ-N variable. These results clearly indicated a role for psychological coping resources in everyday life for these patients, and sense of humor appeared to play a significant role. 
Aarstad, Aarstad, Heimdal and Olofsson (2005) studied the importance of sense of humor for prognosis and quality of life among seventy-eight male patients with head and neck cancer (squamous cell carcinoma) and sixty-one male patients with benign head-neck diagnoses, excluding patients with cachexia and age above eighty. All completed the Beck Depression Inventory, Spielberger Trait-State Anxiety Inventory, Quality of Life and the SHQ-6. The cancer patients, on average, reported higher anxiety and lower depression levels than the controls. Sense of humor, but not level of anxiety or depression, at diagnosis predicted quality of life and depression at follow-up, with higher quality of life and lower depression among patients scoring high on sense of humor.

\section{SHQ-6 and Mortality}

Research on the role of humor in longevity is sparse. A well-known series of three studies were based upon a carefully selected cohort of bright children in California, eleven years old, initiated by Lewis Terman in the early 1920s ( $N=1,215)$. All adopted a prospective design and tested personality predictors of mortality over the lifespan. They included an index of sense of humor/cheerfulness as seen by teachers and parents. The first of these reports (Friedman, Tucker, Tomlinson-Keasey, Schwartz, Wingard \& Criqui, 1993) had a broad focus on personality and showed that lowconscientious children were at higher risk of premature mortality than were highconscientious children, and children scoring low on the humor index were more likely than those scoring high to achieve an older age. This appeared to be a robust finding that was confirmed in a follow-up report (Friedman, Schwartz, Martin, Tomlinson-Keasey, Wingard \& Criqui, 1995): Cheerful children tended to die early compared with less cheerfulness ones. In a 2002 report, Cheerfulness was the exclusive focus in a third report from this pioneering study, and the positive relationship between childhood cheerfulness and increased mortality was again confirmed (Martin, Friedman, Tucker, Tomlinson-Keasey, Criqui \& Schwartz, 2002).

In contrast, a positive relation between humor and longevity was reported in a more recent study of mortality among end-stage renal failure patients (Svebak, Kristoffersen \& Aasarød, 2006). These investigators assessed sense of humor among a county cohort ( $N=48$ ) of renal failure patients using the SHQ-6. Their study employed a two-year prospective design and included a number of other measures that might influence health outcome, such as biomedical indices of severity of the disease, duration of the renal failure, age, gender and quality of life. The strongest predictor of survival in this cohort was the sense of humor score, and those with higher scores 
had around a $30 \%$ reduced risk of dying, compared with those scoring in the lower half of the distribution on the SHQ-6.

There were a number of striking differences between the above two research approaches, including the participant samples, the prospective time periods and the methods for assessing sense of humor. The Friedman group estimated differences in cheerfulness based upon the social image of the child as seen by their teachers and parents, whereas the renal failure study assessed differences in sense of humor based upon self-image. Both studies call upon replications with recruitment of broader populations in order to evaluate the importance of assessment by social image versus self-image of sense of humor.

The Ultra-Short SHQ-3

The largest population health screening survey appears to have been in Norway over the last 25 years. Health screening has been performed of a county population, aged above nineteen, at three times with approximately ten years between screenings, starting in the mid 1980's. The screening is referred to as the HUNT-1, -2, and -3 , respectively (county of North-Trøndelag). In HUNT-2 my primary responsibility was to uncover the prevalence of musculoskeletal pain and discomfort, which left little room for assessing sense of humor as well. The health survey included an extensive set of variables addressing health issues across a range of research interests. Therefore, a need for overall brevity in the survey was pivotal to ensure a high level of participation. Thus, humor was assessed by one question from each of the three sets of items in the SHQ (Svebak, 1996). Item selection was based upon the highest factor loading for each of the three items within their dimension. These were as follows: "Do you easily recognize a mark of humorous intent?" (M-item; N= 53,546; standardized ite $\mathrm{m}$ alpha $=.91$, item correlating .87 with sub-scale sum); "Persons who are out to be funny are really irresponsible types not to be relied upon" (L-item; $\mathrm{N}=52,198$; standardized item alpha $=.91$, item correlating .88 with sub-scale sum); and "Do you consider yourself to be a mirthful person?" (E-item; $N=53,132$; standardized item alpha $=.74$, item correlating .78 with sub-scale sum). The participants responded to 4-step scales (labelled for the three items respectively: very sluggishly - very easily; yes indeed - not at all; not at all - yes indeed). Given the extreme brevity of this approach, scores were summed into one index of sense of humor.

A detailed account of the SHQ-3 item scores and their distribution across age cohorts has been published (Svebak, Martin \& Holmen, 2004). Results were based upon 
responses from 26,850 males and 28,550 females across the whole age span from above age 19. Total scores were slightly skewed toward the high end and declined slightly with increasing age after fifty and were slightly higher in males than females up to age fifty. Above age seventy, females, on average, scored slightly higher than males. Correlations with health parameters were trivial. Thus, health satisfaction was positively correlated with humor scores $(r=.21)$. After controlling for age, only the partial correlation with health satisfaction remained above $.10(r=.12)$. Very low coefficients were significant, due to the large number of participants, despite the fact that shared variance was very low. However, these survey findings clearly confirmed previous findings on lack of a direct and strong relationship for sense of humor with physical health parameters such as dyspepsia, indigestion, cardiorespiratory complaints, musculoskeletal complaints, systolic and diastolic blood pressure and body mass index.

The ultra-short SHQ-3 has been used in a seven-year prospective study of survival among the participants of the HUNT-2 and with the SHQ-3 index as predictor of allcause mortality (Svebak, Romundstad \& Holmen, 2010). The sum of scores given to the three items ( $M: N=53,546 ; L: N=52,198 ; E: N=53,132)$ were tested as predictors of survival by Cox survival regression analyses applied to gender, age and subjective health. Findings indicated that hazard ratios (HR) were reduced with sense of humor (continuous scale: $H R=0.73$; high versus low scores by median split: $H R=0.50$ ). These findings were contrasted with an increased HR associated with a number of wellknown risk factors (cardiovascular disease: $H R=6.28$; diabetes: $H R=4.86$; cancer: $H R=4.18$; poor subjective health: $H R=2.89$ ). Gender was of trivial importance to the effect of sense of humor on survival. Subjective health correlated positively with sense of humor. It is therefore possible that subjective health could be the real cause of a spurious relation of increased survival with a high sense of humor. However, sense of humor proved to reduce HR both in individuals with poor and good subjective health. Interestingly, above age sixty-five the effect of sense of humor on survival became less evident, and beyond age seventy-five the Caplan-Meyer survival curves for the high versus low sense of humor groups were undistinguishable. Therefore, sense of humor appeared to increase the probability of survival into retirement, and this effect appeared independent of subjective health. It was not at all present after age seventy-five. We do not conclude that sense of humor is of trivial importance to psychosocial quality of life after seventy-five.

\section{Conclusion}

The present conceptual approach focused upon three components of sense of humor. It took two revisions to have a test with seven items on each sub-scale and 
fair internal consistency for the $M$ - and L-items. The moderate internal consistency of the E-items was taken as due to the diverse sources of laughter beyond humor and, therefore, further revision has been discouraged. Total SHQ-scores predicted amount of laughter when exposed to comedy in the laboratory. Gender differences generally has not been supported for sense of humor, despite support for sex role stereotypes for different subscales. Higher SHQ-scores have been found among adolescents living in rural as opposed to urban settings. Higher $\mathrm{M}$ - and L-scores have been associated with greater self-esteem, extraversion, optimism, wellbeing, and lower neuroticism and depression. The studies using $M$ - and L-items also support a moderating role for sense of humor in effects of stress upon negative moods, bo dily complaints and Ig-A. Research using the short SHQ-6 has supported a role for sense of humor in coping with bodily diseases. High scores have been associated with better coping and reduced complaints. Pioneering support for the role of sense of humor in increased survival was reported in a prospective study of patients with endstage renal failure. This finding was supported by scores on the ultra-short SHQ-3 in a large-scale adult county population health survey where mortality after seven years into follow-up was approximately $30 \%$ lower among those scoring high compared with those scoring low. The SHQ-6 and SHQ-3 are recommended when a short scale for the assessment of sense of humor is needed.

\section{References}

Aarstad, H. J., Aarstad, A. K., Heimdal, J. H., \& Olofsson, J. (2005). Mood, anxiety and sense of humor in head and neck cancer patients in relation to disease stage, prognosis and quality of life. Acta Oto-laryngologica, 125, 557-565.

Apter, M. J. (1982). The experience of motivation: The theory of psychological reversals. London: Academic Press.

Andrews, T. G. (1943). A factor analysis of response to the comic as a study in personality. Journal of General Psychology, 28, 209-224.

Beermann, U., \& Ruch, W. (2009). How virtuous is humor? What we can learn from current instruments. The Journal of Positive Psychology, 4, 528-539.

Bergen, D. (2009). Gifted children's humor preferences, sense of humor, and comprehension of riddles. Humor: International Journal of Humor Research, 22, 419-436.

Cattell, R. B., \& Luborsky, L. B. (1947). Personality factors in response to humor. Journal of Abnormal and Social Psychology, 42, 402-421. 
Deaner, S. L., \& McConatha, J. T. (1993). The relation of humor to depression and personality. Psychological Reports, 72, 755-763.

Doris, J., \& Fierman, E. (1956). Humor and anxiety. Journal of Abnormal and Social Psychology, 56, 59-62.

Eysenck, H. J. (1942). The appreciation of humour: An experimental and theoretical study. British Journal of Psychology, 32, 295-309.

Franzini, L. R. (1996). Feminism and women's sense of humor. Sex Roles, 35, 811-819.

Franzini, L. R., \& Hoggarty, S. (1994). Humor assessment of corporate managers and humor seminar and personality students. Humor: International Journal of Humor Research, 7, 341-350.

Friedman, H. S., Schwartz, J. E., Martin, L. R., Tomlinson-Keasey, C., Wingard, D. L., \& Criqui, M. H. (1995). Childhood conscientiousness and longevity: Health behaviors and cause of death. Journal of Personality and Social Psychology, 68, 696-703.

Friedman, H. S., Tucker, J. S., Tomlinson-Keasey, C., Schwartz, J. E., Wingard, D. L., Criqui, M. H. (1993). Does childhood personality predict longevity? Journal of Personality and Social Psychology, 65, 176-185.

Giles, H., \& Oxford, G. S. (1970). Tow ards a multidimensional theory of laughter causation and its social implications. Bulletin of the British Psychological Society, 23, 97-105.

Götestam, K. G., Svebak, S., \& Jensen, E. N. (2008). The role of personality, mood, subjective health, and stress in depressive symptoms among high school students. The European Journal of Psychiatry, 22, 121-129.

Helvik, A. S., Jacobsen, G., Svebak, S., \& Hallberg, R.-M. (2007). Hearing impairment, sense of humour and communication strategies. Scandinavian Journal of Disability Research, 9, 1-13.

Kambouropoulou, P. Individual differences in the sense of humor. American Journal of Psychology, 37, 268-278.

Kuiper, N. A., \& Martin, R. A. (1993). Humor and self-concept. Humor: International Journal of Humor Research, 6, 251-270.

Kuiper, N. A., \& Martin, R. A. (1998). Is sense of humor a positive personality characteristic? In W. Ruch (Ed.), The sense of humor: Explorations of a personality characteristic (pp. 159-178). Berlin: Walter de Gruyter. 
Kuiper, N. A., Martin, R. A., \& Dance, K. A. (1992). Sense of humour and enhanced quality of life. Personality and Individual Differences, 13, 1273-1283.

Kuiper, N. A., \& Nicoll, S. (2004). Thoughts of feeling better? Sense of humor and physical health. Humor: International Journal of Humor Research, 17, 37-66.

Lefcourt, H. M., \& Martin, R. A. (1986) Humor and life stress: Antidote to adversity. New York: Springer-Verlag.

Martin, L. R., Friedman, H. S., Tucker, J.S., Tomlinson-Keasey, C., Criqui, H., \& Schw artz, J. E. (2002). A life course perspective on childhood cheerfulness and its relation to mortality risk. Personality and Social Psychology Bulletin, 28, 1155-1165.

Martin, R. A. (2007). The psychology of humor: An integrative approach. New York: Academic Press.

Martin, R. A., \& Dobbin, J. P. (1988). Sense of humor, hassles and immunoglobulin A: Evidence for a stress-moderating effect of humor. International Journal of Psychiatry in Medicine, 18, 93-105.

Martin, R. A., Puhlik-Doris, P., Larsen, G., Gray, J., \& Weir, K. (2003). Individual differences in uses of humor and their relation to psychological well-being: Development of the Humor Styles Questionnaire. Journal of Research in Personality, 2003, 37, 48-75.

MCNair, D. M., Lorr, M., \& Droppelman, L. F. (1971). The Profile of Mood States. San Diego: EDITS.

Naper Jensen, E., Svebak, S., \& Götestam, K. G. (2004). A descriptive study of personality, health and stress in high-school students (16-19 years old). European Journal of Psychiatry, 18, 153-162.

O'Connell, W. E. (1969). The social aspects of wit and humor. Journal of Social Psychology, 79, 183-187.

Randler, C. (2008). Evening types among German university students score higher on sense of humor after controlling for big five personality factors. Psychological Reports, $103,361-370$.

Ruch, W. (ed.) (1998). The sense of humor: Explorations of a personality characteristic. New York: Mouton de Gruyter. 
Sandler, I. N., \& Lakey, B. (1982). Locus of control as a stress moderator: The role of control perceptions and social support. American Journal of Community Psychology, 10, 65-80.

Svebak, S. (1969). Latterens psykologi: En teoretisk model og et psykofysiologisk eksperiment (The psychology of laughter: A theoretical model and a psychophysiological experiment). University of Oslo (Master's thesis).

Svebak, S. (1974a). A theory of sense of humor. Scandinavian Journal of Psychology, 15, 99-107.

Svebak, S. (1974b). Three attitude dimensions of sense of humor as predictors of laughter. Scandinavian Journal of Psychology, 15, 185-190.

Svebak, S. (1974c). Revised questionnaire on the sense of humor. Scandinavian Journal of Psychology, 15, 328-331.

Svebak, S. (1993). The development of the Tension and Effort Stress Inventory (TESI). In J. H. Kerr, Murgatroyd, S. \& Apter, M. J. (Eds.), Advances in reversal theory (pp. 189-204). Amsterdam: Swets \& Zeitlinger.

Svebak, S. (1996). The development of the Sense of Humor Questionnaire: From SHQ to SHQ-6. Humor: International Journal of Humor Research, 9, 341-361.

Svebak, S., Götestam, K. G., \& Jensen, E. N. (2004). The significance of sense of humor, life regard, and stressors for bodily complaints among high school students. Humor: International Journal of Humor Research, 17, 67-83.

Svebak, S., Kristoffersen, B., \& Aasarød, K. (2006). Sense of humor and survival among a county cohort of patients with end-stage renal failure: A two-year prospective study. International Journal of Psychiatry in Medicine, 36, 269-281.

Svebak, S., Naper Jensen, E., \& Götestam, K. G. (2008). Some health effects of implementing school nursing in a Norwegian high school: A controlled study. Journal of School Nursing, 24, 49-54.

Svebak, S., \& Martin, R. A. (1997). Humor as a form of coping. In S. Svebak, \& M. J. Apter (Eds.), Stress and health: A reversal theory perspective (pp. 173-184). Tylor and Francis, Washington DC, Tylor and Francis. 
Svebak, S., Martin, R. A., \& Holmen, J. (2004). The prevalence of sense of humor in a large, unselected county population in Nonway: Relations with age, sex, and some health indicators. Humor: International Journal of Humor Research, 17, 121-134.

Svebak, S., Søndenaa, K., Hausken, T., Søreide, O., Hammar, A., \& Berstad, A. (2000). The significance of personality in pain from gallbladder stones. Scandinavian Journal of Gastroenterology, 35, 759-64.

Svebak, S., Romundstad, S., \& Holmen, J. (i2010). A seven-year prospective study of sense of humor and mortality in an adult county population: The HUNT-2 study. International Journal of Psychiatry in Medicine. 40, 125-146.

Ursin, H., Endresen, I. M., \& Ursin, G. (1988). Psychological factors and self-reports of muscle pain. European Journal of Applied Psychology, 52, 282-290.

Wolff, H. A., Smith, C. E., \& Murray, H. A. (1934). The psychology of humor. Journal of Abnormal and Social Psychology, 28, 341-365.

About the author:

Sven Svebak is professor of medicine (behavioural sciences in medicine) at the Norwegian University of Science and Technology, Trondheim, Norway. He is a licenced psychologist and worked as research psychophysiologist un til he resigned as full professor from the Faculty of Psychology, University of Bergen, in 1994. His dissertation reported a series of experiments on psychophysiological differences between serious-minded versus playful motivational involvement in continuous perceptual-motor task performance. His research focus over fourty years has mainly been divided between sense of humor (subjective health, morbidity, mortality) and musculoskeletal tension and pain (mechanisms, prevalence, interventions). He has worked for fifteen years as adjunct clinician and researcher in a multidisciplinary team for the rehabilitation of patients with chronic back pain and has published on prevalence of musculoskeletal pain from one of the largest public health surveys of the world (HUNT-2) where he also initiated the pioneering population study on sense of humor and survival.

Address for correspondence: Sven Svebak, Department of Neuroscience, Nevro øst 3. etg., NO-7496 Trondheim, Norway.

E-mail address: sven.svebak@ntnu.no or sven.svebak@yahoo.com 